\title{
Real and Illusory Architectures in the Pompeian Frescoes
}

\author{
Barbara Messina' ${ }^{1}$ Maria Ines Pascariello ${ }^{2}$
}

Published online: 6 July 2016

(C) Kim Williams Books, Turin 2016

\begin{abstract}
This paper shows the results of a series of graphical experiments conducted as part of a PRIN research project on the ancient architectural perspectives in Campania. The study was undertaken by the Universities of Salerno and Naples. Critically studying the origin, the development and the magnification of the perspective, we try to emphasize the power of this method, that alludes to the space's three-dimensionality. Particularly, the paper is focused on the frescoes of the Poppaea's villa, in Oplontis: through rigorous photogrammetric procedures of reverse modelling, which reconstruct their not real architectures, it is possible to clarify the project of illusion, implemented by these paintings. The analysis of its frescoes' perspective illusions, allows us to reconstruct there presented architectures and the virtual space that they conform. Then, the use of advanced technologies allows to create an unusual visual experience which, linking the real space and the drawn one, shows the influences between painted and built space.
\end{abstract}

\section{Architectural Perspectives in Pompeii}

The painting heritage produced during the Roman age in the Campania region of Italy, and especially in the area around Mount Vesuvius, undeniably constitutes a fundamental premise for all general studies focusing on the relationship between

Barbara Messina

bmessina@unisa.it

Maria Ines Pascariello

mipascar@unina.it

1 Department of Civil Engineering, University of Salerno, via Giovanni Paolo II, 132, 84084 Fisciano, SA, Italy

2 Department of Civil, Architectural and Environmental, University of Naples "Federico II", via Claudio 21, 80125 Naples, Italy 
architecture and perspective. Of course, perspective would only be coded several centuries later but it must be recognized that Roman art-particularly in Pompeiihas the merit of representing architecture according to figurative canons that, although intuitive, allude to depth of space $^{1}$ in an extremely convincing way.

The iconographic repertory of architecture in Campania constitutes a highly significant corpus of images. This is not only because it is extensive and largely undamaged, but also because it is totally unique in terms of figurative content, as it provides an ante litteram expression of a virtual reality simulating illusory spaces that, in many cases, were probably conceived and designed down to the smallest details.

These considerations have led to some reflections and investigations on the wall paintings - especially the frescoes - that characterise the aforesaid archaeological heritage, which has recently been the object of research conducted by the University of Salerno, the University of Naples Federico II and the Second University of Naples as part of a national project aiming to promote and spread awareness of the Italian architectural perspectives (Cardone 2014). It was immediately obvious that this would be a particularly delicate and complex task considering, on the one hand, the cultural, historical and artistic value of the works involved and, on the other, the sheer magnitude, in both quantitative and qualitative terms, of the entire heritage considered.

With reference to the number of architectural frescoes and images, it is firstly important to focus on the approximately 270 "building-containers" in which the painted architectures can be found. Particularly, if we focus on the most common constructions which are the domus, farms and other private or public buildings, each of them contains a number of frescoed areas and often, within the individual areas, there are several walls with architectural perspectives.

Thus, to give an idea of the quantity of items that make up the perspective figurative repertory, and referring to data from an early exploratory campaign, each building is estimated as having an average of between two and three frescoed areas and five or six architecture-painted walls. Despite being purely indicative, this information perfectly conveys the wealth of the investigated heritage, which comprises approximately 750 areas and 1300 frescoes useful for the research.

However, more important examples have to be added to these, such as the villae of the wealthier classes, which count a significantly higher number of frescoes. For instance, Poppaea's imperial villa at Oplontis, which belonged to the Emperor Nero's second wife around the mid first century AD and was later extended during the Claudian age, contains over twenty perspective frescoes of illusory architecture, thus constituting fundamental graphic evidence for the reconstruction of living space in the roman age in which the real and imaginative dimensions coexist and often overlap.

Typologically speaking, that is to say by examining the figurative themes that connote the whole iconographic heritage studied, significant differences can be

\footnotetext{
${ }^{1}$ For this reason, De Rosa remarks that Greek art had already attempted to represent the visual appearance of things, alluding to the third dimension that had never previously been mentioned. There are very few graphic testimonies of this production; in order to reconstruct what can be called visual realism, we have some references in literature (De Rosa 2000).
} 
found according to the period in which the architectural frescoes were produced. Hence there are four specific pictorial styles in Pompeii corresponding to the successive historical periods, each characterized by its own compositional and representational style. While referring the reader to a more accurate analysis for a complete reading of the features that characterize each of these, here we aim to focus on the frescoes of the second and fourth styles, in which the depiction of space acquires a dramatic connotation through the albeit intuitive use of perspective, which is here represented in a truly spectacular way (Mau 1882).

Specifically, the main aim of the paper is to clarify the close bond that the illusory space, i.e., the painted space simulating real space, establishes with the architecture that contains it, to the extent that it is possible to imagine and then represent the simulated space as a complementary part of the real space. The following sections of this paper define the parameters of a rigorous project of illusion, which underlies the architectures and spaces depicted, and reconstructs the architecture integrated into the illusion as if it were real, by means of software-based solid modelling and rendering techniques, which have made a considerable contribution to the simulation of virtual spaces in this experiment.

\section{Ancient Perspective Between Codification and Intuition}

Linear conical perspective makes it possible not only to represent our perception of space on drawings and paintings but also to achieve effects on the whole decoration. These effects lead us to perceive not the actual spatial reality but a totally fictitious reality created by the illusion of perspective (Sgrosso 1984).

The search for spatial representation often coincides with the search for the means to achieve it. Such tools are provided, sometimes rigorously and sometimes empirically, by geometry and represent the choices that are made according to the dominant tendencies and according to the different artistic spirit of each historical period. In this way, perspective turns out to be an extraordinary intellectual construction, a brilliant mathematical invention that requires an infinite and homogeneous space in which empty has the same value as full and the objects and the space that divides them establish an indestructible union observed from a unique and unmovable point of view.

It should be noted that, chronologically speaking, pictorial wall decorations first appeared in the towns of Campania, and August Mau, the German archaeologist who first conducted a systematic study of ancient Pompeii's paintings, divided them into four following styles (Mau 1882).

The first style is also called incrustation (from the Latin word crusta indicating the ornamental coating of thin layers of marble or other prized materials) and was used in public buildings and in reception areas of private buildings starting from 150 $\mathrm{BC}$ up to $80 \mathrm{BC}$. Throughout most of the first century BC, the architectural themes of the second style take over in wall paintings and decorations. Between the ages of Augustus and Nero (20 BC-50 AD) a new and decorative third style spreads, which has also been influenced by the passage from the Republic to the Empire. The period between $50 \mathrm{AD}$ and the eruption of Mount Vesuvius in $79 \mathrm{AD}$ saw the birth and 
diffusion of a final fourth style, the prime examples of which were to be found in Nero's great constructions.

It was the second style of Pompeian painting in particular that used perspective to represent sensorial reality. In this way the image could coincide with the real point of view and rationalize the image of space sensed and represented without strict rules. Only following the scientific theory and the geometrical procedures formulated by Renaissance artists was the perspective representation of space oriented in a conventional and intellectual direction, offering artists the possibility to use mathematical procedures while not conditioning their creative freedom or view of the world.

However, at a first glance the paintings of the second style look like architectural perspectives created under the Renaissance rules: at this point, the problem is to determine whether the ancients understood and used the perspective construction as we know it, or whether the spatial representation they used was actually random. In fact, ancient paintings, and especially those in the second style, were all created according to the same basic pattern, although with several imaginative variations, which leads us to reject the hypothesis of a random representation of space. From an analysis and comparison of the various architectures depicted in the second style, we can firstly identify a pictorial type that is common to all the frescoes of the style: a foreground that serves as a frame around the core of the representation, as if it were a sort of faux window opening in the wall; a middle distance in which columns support trabeations or a coffered ceiling; and in the background beyond the columns, a garden. So we can speak of a layered or even broken perspective, in which the represented space is an aggregation of several topics (Damisch 1987).

At this point it is worth mentioning the Panofsky theory, according to which the ancients, especially in the Roman Hellenistic period, actually coded their own perspective system, a curved perspective, with a single vanishing axis, which corresponds to the classical notion of space as a non-continuous entity, an area of conflict between full and empty, just as plane perspective is in relation with the modern conception of an infinite and homogeneous space (Panofsky 1927). Obviously it is not easy to define the terms of the ancients' curved space: in fact, it rather seems as if the classic period never reached a coherent solution to some difficulties that are directly connected to the spatial problem, such as those regarding the relationship between the finite and the infinite. These difficulties were allowed to live, and their solutions were only found through a progressive and radical modification in human spiritual attitude. The inadequate dominion of spatiality on a theoretical level has its parallel in the non-coherence that is typical of the curve perspective, and in particular of the vanishing axis constructiondominant throughout the Middle Ages-which occasionally had to be masked by a fig leaf drawn in perspective (Panofsky 1927).

This contradictory nature of the idea of space obviously does not exclude the possibility for the ancient world to express a precise spatial sentiment, which was well documented by the second style; in fact the technique for representing this space and the architectures that define it constitute the most interesting paintings of the second style. A representation which Lessing, in the ninth of his Letters in 1775, had already defined as perspective, underlining that denying the ancients were 
aware of perspective in its broader meaning would be crazy, because that would mean denying not perspective but the painting art in which they best succeeded.

As he notes, he believes that painting in the time of Homer was still in its infancy, not merely on the authority of Pliny, or some other writer, but chiefly because, judging from the works of art mentioned by the ancients, he sees that even centuries later no great progress had been made. The pictures of Polygnotus, for instance, by no means stand the test which Pope thinks can be successfully applied to Homer's shield. The two great works by this master at Delphi, of which Pausanias has left a circumstantial description, were evidently wholly wanting in perspective. The ancients had no knowledge of this branch of art, and what Pope adduces as proof that Homer understood it, only proves that he has a very imperfect understanding of it himself. That Homer, he says, was not a stranger to aerial perspective appears in his expressly marking the distance of object from object. He tells us, for instance, that the two spies lay a little remote from the other figures, and that the oak under which was spread the banquet of the reapers stood apart. What he says of the valley sprinkled all over with cottages and flocks appears to be a description of a large country in perspective. And, indeed, a general argument for this may be drawn from the number of figures on the shield, which could not be all expressed in their full size (Lessing 1775).

A more recent critical movement appears to be oriented in the same direction, and recognizes the ancients' usage of modern perspective: Gioseffi, for instance, starts from an essay by Beyen (1939) who, reacting to the general belief that the ancients did not use modern perspective, wanted to prove its theoretical and practical knowledge in the classical world, leaning on the testimony of some Pompeian frescoes of the second style, created more or less correctly in relation to a common vanishing point.

Gioseffi shares Beyen's opinion and proposes a new proof in these terms, a proof that, despite the substantial methodological seriousness and validity, nevertheless reveals its limits through the very words of the author (Panofsky 1927): Gioseffi's essay states that the ancient paintings representing buildings that survive, in the majority of the cases, present perspectives with some approximations; the others, the rigorous ones, are just a small minority and are not free from arbitrariness and contaminations (Gioseffi 1957).

For Gioseffi this becomes the starting point to continue with his proof: later he faces the difficult challenge of proving the uniqueness of perspective in all the times and places of the history of art-from Pompeian to Byzantine painting, from Giotto to Brunelleschi, from Alberti to Leonardo and the Galli Bibiena family-and to test their absolute scientific validity and coherence to visual reality. Referring both to Descriptive Geometry and Optics, Gioseffi proves the scientific inconsistency of each curve perspective: the proof is circumstantiated and rigorous and the fundamental axiom is the one according to which the perspective picture and the natural vision of an object coincide and result in a single image on the retina as long as in both cases there is monocular vision with an immobile eye at the right distance (Gioseffi 1957).

This type of vision is thus strongly linked to the ancient representation of perspective, rigorously connoting it and declining, in recurring, continuous and 
recognizable forms, a representation that, despite not being supported by rigorous system of precepts such as that used in the Renaissance, appears in several declinations as a scientific representation coherent to visual reality (Wunenburger 1997).

\section{Digital Use of Illusory Architectures in Pompeii's Painting}

Pompeii's painting from the second and fourth styles relies on the perspective structuring of the image in order to evoke an illusory space that virtually amplifies the real space. We can, therefore, understand how important it may be to propose an interpretative method for these architectural perspectives that, by means of several useful infographic techniques and procedures, may lead to the complete fruition of Campania's archaeological buildings by investigating their real and depicted architecture. The architectures depicted in Pompeii's frescoes-which are the decoration of halls and triclinia destined for official receptions, meetings and conviviality, but also of more private spaces destined for family use, like cubicula and alcoves - are in fact the image of an alternative reality that interacts with the tangible one. In a magical game of layering, the real space enters the image, which evokes concrete elements with such fine detail that they are almost made real. On the contrary, the illusory space of frescoes merges with the physical space, enlarging its boundaries and simulating, in a profoundness which is often impossible to achieve, non-material rooms that complete the real space, without contradicting it (Argan 1983) (see Fig. 1). Pictorial representation thus makes it possible to surpass the physical limits of the walls that, almost like a veil between the painter and the object, mark the transition from the physical to the imaginary space. Pompeii's

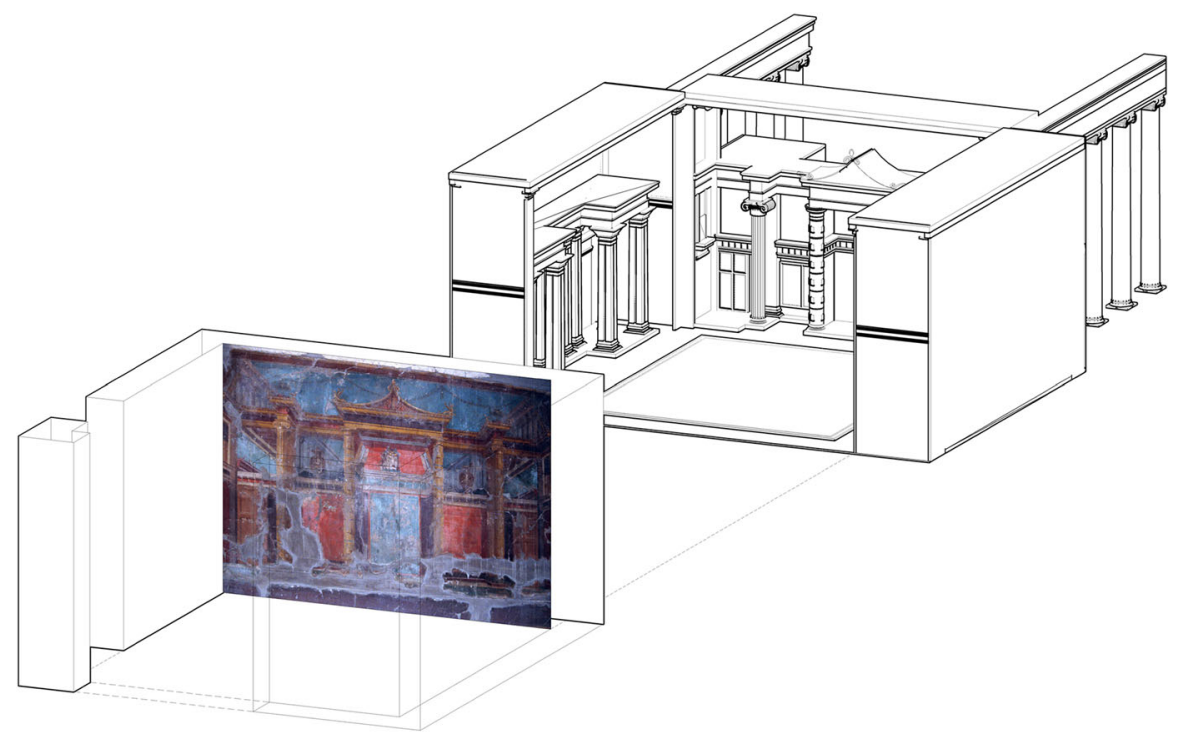

Fig. 1 Oplontis, villa of Poppaea: Hall of the Pomegranates. Real space and virtual space 
artists thus seem to be engaged in a figurative quest that can be defined as experimental for the time, to 'capture' the third dimension and drag it into the plane, alluding to a non-existing spatiality that is proposed as visually possible. And it is this kind of illusionistic weaving of real and virtual that makes Pompeii's pictorial wall art extraordinarily topical: many centuries ahead of its time, it proposes the idea of integrating real and imaginary architectures achieved through the evocative power of perspective drawing.

Perspective architectures from Pompeii's pictorial art thus convey a sense of interpenetration of the real and the virtual, typical of the most recent systems of technological and visual communication of architectural space, which is rooted further back in time. While acknowledging the differences due to the obvious potential offered by modern technology, the intuitive architectural perspectives of ancient Rome, and the more scientific perspectives of the Renaissance, seem to anticipate the illusory world that is today proposed by augmented reality and offers the observer the possibility of participating in the depicted space, which means entering an alternative reality.

In this framework and with a view to proposing innovative systems and forms for the visual communication of Campania's architectural heritage in paintings, the research aims to test a scientific computerized approach in order to verify the role of representation, when used as an advanced documentary and cognitive tool. Accordingly, the aim is also to determine how, by exploiting the potential of the graphic instrument, suitable strategies for the protection and valorisation of such an important and complex archaeological and iconographic heritage as Pompeii's can be identified (Fig. 2).

Emblematic for the research is Poppaea's villa in Oplontis (Pascariello 2009): the presence of a fundamentally undamaged corpus of frescoes with perspective scenes makes it a particularly suitable model to test the validity of a scientific method that points to the correct three-dimensional fruition of the examined architecture, representing not only the physical space but also the illusory reality depicted on the walls. It is a question of producing infographic models by interpreting and translating the geometric and morphological qualities of the depicted architectures, ideally as an integral part of the rooms incorporating them and which appear to be enlarged by them.
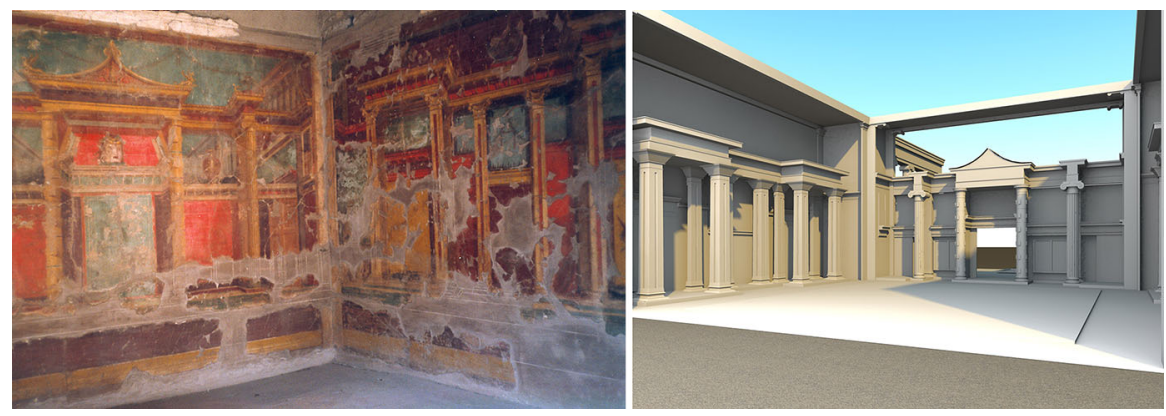

Fig. 2 Oplontis, villa of Poppaea: Hall of the Pomegranates. Painted architecture (left) and painted space's rendering. (Processed by G. Manzo; coordinators B. Messina, M. I. Pascariello) 
This is equivalent to trying to retrace the logic underlying the project of these illusory architectures, while recognising that if "designing" means anticipating the construct by studying its shapes and the possible executive modes, the conception of the imagined space is only achieved through drawing design that offers the perception a fictitious reality conceived through imagination.

\section{From Frescoes to Virtual Space}

In order to achieve the correct interpretation of the spatiality evoked by the perspective images that can be found in many rooms of the villa, it appeared necessary to use rigorous geometric and photogrammetric procedures, by means of which all the useful metric and morphological information was obtained for the subsequent definition of the infographic models.

The transition from the projective image of the depicted scene to the descriptive representation of orthogonal projections was a particularly delicate step. In this phase, which follows the process of representing space in reverse, a great deal of data can be subjected to critical interpretation by the operator. Therefore, the operator has to have a particular sensibility and a deep historical and artistic knowledge so that (s)he can go beyond a mere reading of the metric data gained through geometrical processes. These are not photographic images for which there exists a single point of view and which allow the use of automatic techniques with photogrammetric software. Although Oplontis's depicted perspectives have been optically verified, a deeper analysis reveals the typical discrepancies of the perspective images produced by Roman arts. ${ }^{2}$

In some cases the whole figuration appears governed by a single geometric rule that regulates the space, except for small exceptions regarding primarily furnishings, which are often drawn in pseudo-axonometric view, or architectural elements arranged in an eccentric position with respect to the visual field, or even subjects far in the background of the composition. While for the first elements the correct perspective was redrawn, in the other cases the convergence to the original vanishing point was respected, obtaining, in orthogonal projections, elements or parts of buildings placed in a non-frontal position compared to the iconic plane (Fig. 3).

In other wall paintings we find the coexistence of several points of view within the single scenes, and consequently there were more horizon lines and more ground planes to which the individual portion of the drawn spaces referred. The presence of several references within each image implies the need to give various reverse perspectives for homogeneous parts of the figuration, thus obtaining several orthogonal but separate projections for the same scene. The images thus obtained were then reassembled in order to obtain a single corpus of volumes that, when appropriately represented, are completely understood (Fig. 4).

In many cases, the process of reconstructing the spatial box highlights the need to refine the raw data derived via reverse perspective, by relying on philological research. Where necessary, we performed a metric correction of some elements that

\footnotetext{
${ }^{2}$ On this topic see Panofsky (1927), Dell'Aquila (2002). About the use of perspective in the Roman art also see Migliari (2005).
} 


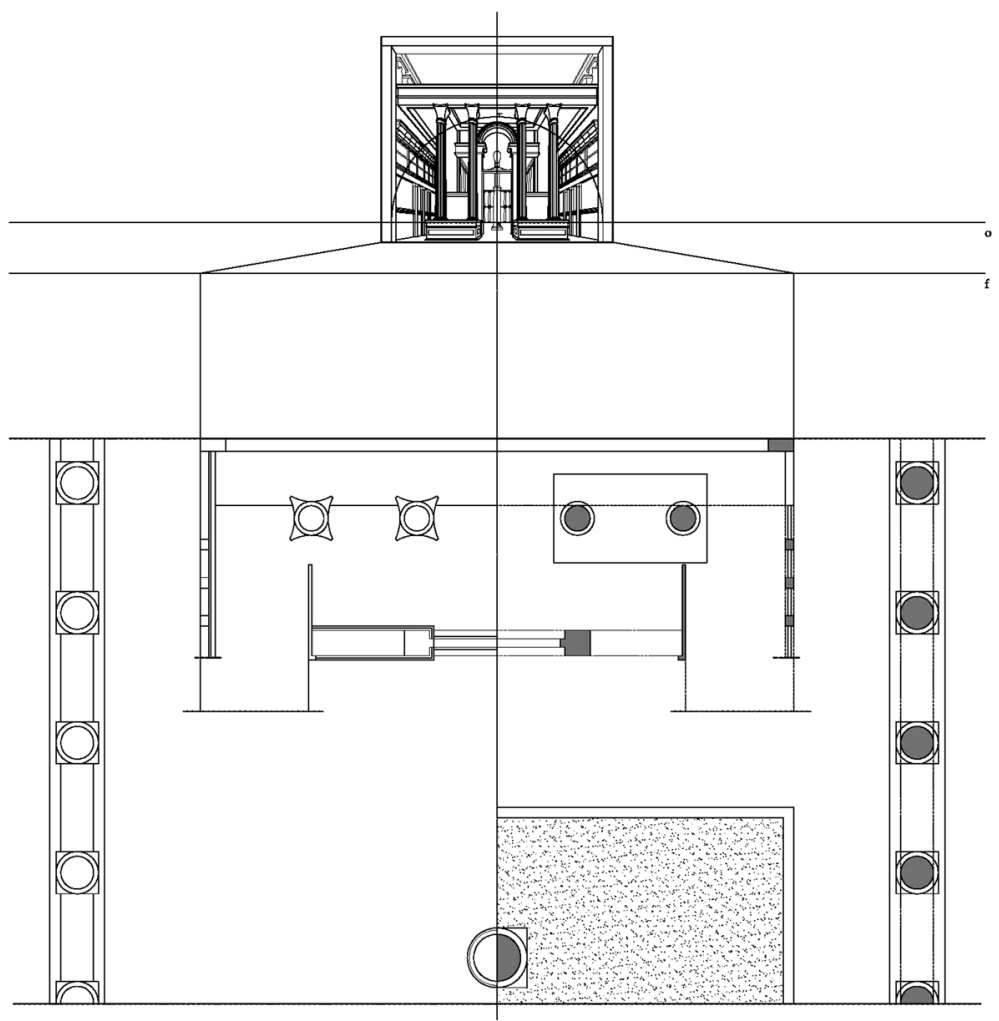

Fig. 3 Oplontis, villa of Poppaea: Main hall. Reverse perspective representation of the illusory architecture through the geometric process of rebatment. Starting from a single frame, we have searched the center of view, the ground line and the horizon line. Then we have deduced the plan of the depicted architecture. (Image processed by M. I. Pascariello)

appeared inconsistent with the rest of the composition and resized them according to a basic module taken as reference for the whole composition, respecting the principles and rules of Roman architecture. Furthermore, we 'rectified' the parts that-perhaps for practical requirements dictated by difficulties in the execution phases-break the reciprocal orthogonality of the planes defining the spatial box.

In any case, the volumetric interpretation of the drawn spaces requires the spatial coherence of the individual elements in each part to be verified with respect to the whole, in order to point out any graphical inconsistencies. Where necessary, our intervention was aimed at making the virtual architectures of the paintings as close as possible to the design objectives that could be gleaned from the scenes themselves. In this way the illusory architectures, which would sometimes include impossible or clearly 'out of scale' spaces, can be made compatible with the hypothetical architectures from the same period of the structure housing them, thus easing the process of visual integration between real and simulated spaces.

Once the necessary metrical information had been gathered, the drawn architectures were reconstructed in a computer graphic environment: the illusory space of the 

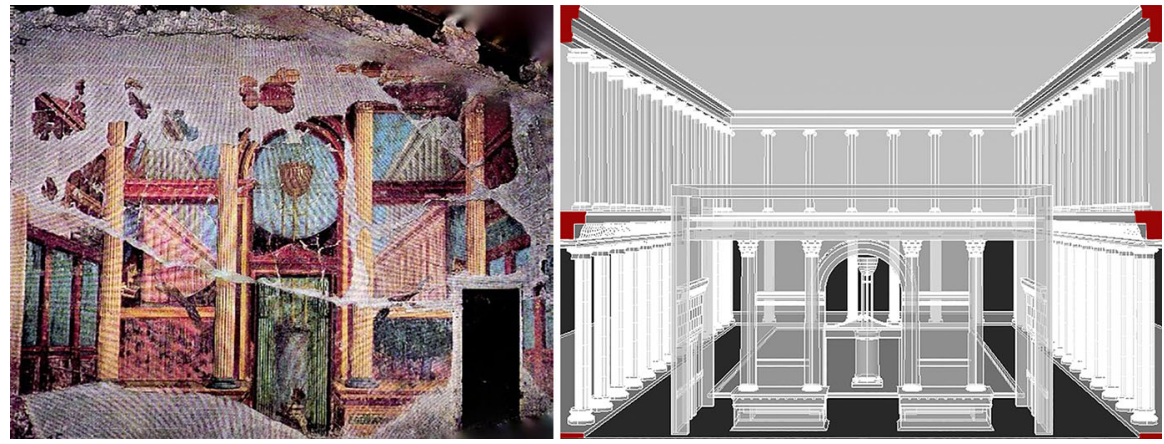

Fig. 4 Oplontis, villa of Poppaea: Salone, painted architecture (left) and perspective (right). Using the inverse perspective technique we can reach the geometric "reconstruction" of the drawn architectures. The virtual space that is rebuilt, is recomposed with the actual surveyed space, through plans, elevations and sections, adding more efficient representations such as perspectives and axonometric views that allow the experience of a brand new space to be captured. (Image processed by B. Messina)

paintings acquired a perceivable three-dimensional nature, even if only in digital reality. In operative terms, it is important to observe that the early models were treated as maquettes, i.e., regardless of materials and textures because in this phase it was important to highlight the quality of the space, more than the nature of the surfaces that build those spaces. Thanks to the techniques and the systems of the infographic representation we could imagine bringing those spaces to life, with their shapes, relations, and complexity. This meant operating in a space-time dimension that was not totally understandable at the time, to represent the compositional and project intentions that can be understood by moving through those architectures, rather than the fixed nature of the represented image. Thanks to digital modelling we can imagine a virtual walk through that environment, giving it the space to which the precious wall paintings allude, multiplying space, virtually adding those fictitious areas drawn in perspective to the real rooms of the villa. This means that we can try to cross the physical limit of the walls, not only with our imagination but also by experiencing an integral perception that is typical of infographic reality (Fig. 5).
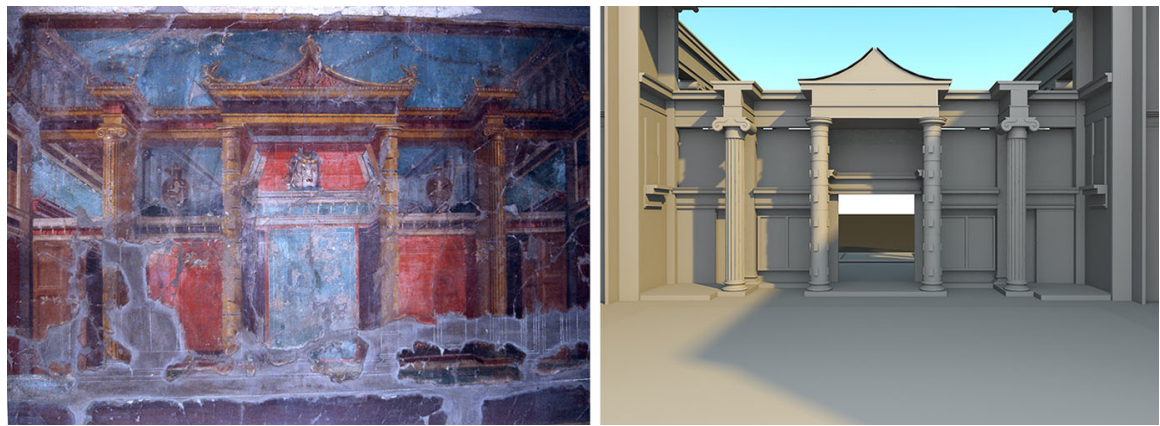

Fig. 5 Oplontis, villa of Poppaea: Sala dei melograni. Comparison between the depicted architecture (left) and the virtual reconstruction (right). (Processed by G. Manzo; coordinators B. Messina, M. I. Pascariello) 
This approach appears extremely interesting and rich in cultural and scientific implications with a view to achieving a cognitive appropriation of the archaeological iconographic heritage being studied, and which can be investigated remotely and independently thanks to the interconnectivity of digital information.

It is therefore a question of defining an agile model for virtual navigation within the architectural space, trying to create an interrelation between real and illusory architectures. This interrelation is obviously very important as it concerns the best known architectural perspectives in Campania's archaeological heritage, for which new forms of scientific presentation can be proposed. The imperial villa at Oplontis is a fine example as it represents the real model through which the validity of the method proposed is to be tested: here the rigorous survey carried out with advanced instrumental techniques, made it possible to digitally rebuild the walls of the whole structure, and this was used to create a virtual tour. The same procedure is proposed
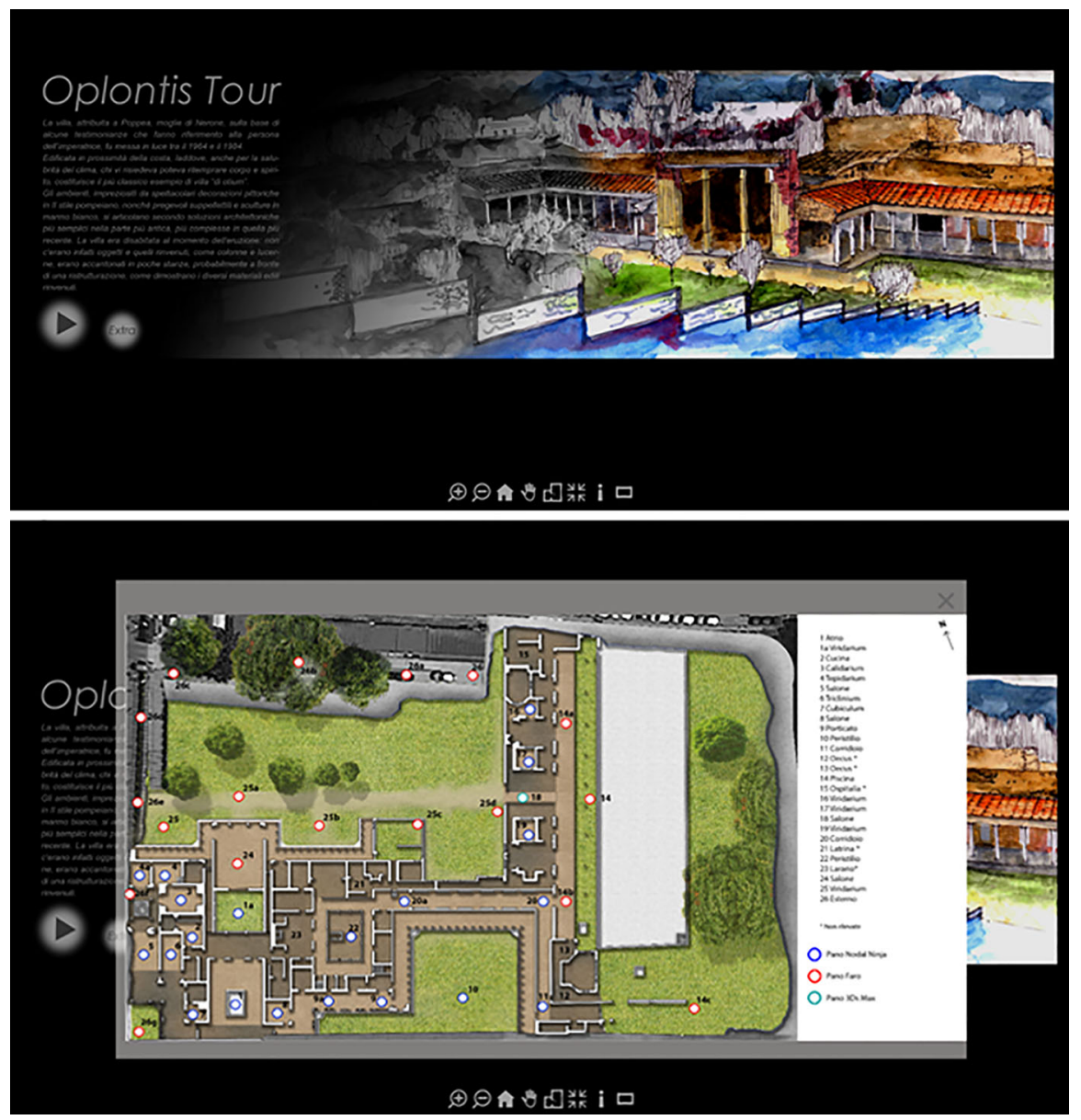

Fig. 6 Oplontis, villa of Poppaea: images of the Virtual Tour application. (Coordinator S. Barba) 
for the depicted architectures, translated into infographic models, for which the experimenting of a procedure to set up virtual tours is taking place, and these will be integrated with those of the real 'container' (Fig. 6).

\section{Conclusions}

The proposed methodology is even more significant if it is referred to all those cases of iconographic heritage in which remote access is the only viable approach. This can have a major impact if we consider that the accessibility to 'architectural perspectives' in Campania proceeds on two parallel but interrelated channels. In other words, with reference both to the building's accessibility and to whether or not the fresco is on site, all possible combinations of use of the architectural iconographic heritage are contemplated.

If we exclude the optimal and complete fruition of both the building and the frescoes, we can envisage a great many cases that are totally excluded from public knowledge. There are many reasons why access to a building-container might be denied: the most common include precarious static conditions or the impossibility of making the building compliant with current laws on safety and accessibility in buildings open to the public; less common situations that condition their freedom of usage might be that the building is, for instance, private property or, as an extreme case, no longer extant.

The latter case-regardless of the condition of the building in which it is located-might mean that the fresco can no longer be used as, in many cases, it has been partially or totally lost. It should be highlighted that the Italian archaeological heritage has frequently been plundered, especially for important and well-preserved frescoes, with the result that the wall paintings are now located elsewhere.

At best, many of the frescoes have been moved to museums throughout the world which, despite their figurative perfection, are totally decontextualized from the structures they were intended for, and hence lose part of the profound sense of the original artwork. To these we can add cases that, although readily viewable and expressing a praiseworthy artistic content, are excluded from effective use as they are classified as less important or because they are not included in the main tour itineraries and are thus only marginally studied.

As far as this partially visible heritage is concerned, it is clearly necessary to offer an alternative possibility for access that enables its popularization and cultural appropriation through the potential of infographic representation. Considering that the iconographic heritage in question comprises drawn architectures that merge with real ones, it is interesting to propose a dynamic interpretative model that can associate the virtual tours of the buildings to the reading of the illusory space, with the aim of achieving its full enjoyment.

Thanks to a sensory involvement, which is much more effective than the static vision of the depicted scene, the observer can grasp, in its entirety, the graphic and artistic strength of such a sophisticated, complex and precious cultural heritage.

We believe that, in this way, we can help to supply a documentary apparatus that could be precious both in communicative terms-if intended for a tourist-type 
user-and in technical-scientific terms, as it is open to consultation and potential implementation by a number of individuals involved in the knowledge and conservation processes of the iconographic heritage, thus promoting the valorisation not only of the cases known to the general public but also of the less famous ones that contribute to making this heritage unique.

Acknowledgments The paper explicates some of the outcomes of a broader experiment on the forms of visual communication and disclosure of the architectural pictorial heritage in Campania, conducted by the research group from the universities of Salerno and Naples Federico II, within a national research project (PRIN 2010-2011 Architectural Perspective: digital preservation, content access and analytics, national scientific coordinator R. Migliari; coordinator of research University of Salerno, with the annexed branches-University of Naples 'Federico II', Second University of Naples, University of Basilicata-V. Cardone). The project was financed by the Italian Ministry of Education, University and Research (MIUR). This work includes the individual contribution of each author. Specifically, Barbara Messina described the adopted methodology (in the following sections: Architectural Perspectives in Pompeii, Digital Use of Illusory Architectures in Pompeii's Painting, From Frescoes to Virtual Space and Conclusions) while Maria Ines Pascariello dealt with the Pompeian styles (in the section Ancient Perspective Between Codification and Intuition). Finally, the University of Salerno research group coordinated by Salvatore Barba, dealt with the operations at the villa in Oplontis and supplied the images from the resulting virtual tour.

\section{References}

Argan, Giulio Carlo. 1983. Pittura e Architettura. In Enciclopedia Universale dell'Arte, X, 626-635. Novara: Istituto Geografico De Agostini.

Beyen, Hendrik G. 1939. Die Antike Zentralperspektive. In Archäologie. Anzeiger des Jahrbuch des dutschen archäol Institut.

Cardone, Vito. 2014. Un Approccio Innovativo allo Studio delle Prospettive Architettoniche di Campania e Basilicata. In Prospettive Architettoniche. Conservazione Digitale, Divulgazione e Studio, ed. Graziano Valenti, 49-60. Roma: Sapienza Università Editrice.

Damisch, Hubert. 1987. L'Origine de la Perspective. Paris: Flammarion.

Dell'Aquila, Mariella. 2002. Lo Spazio Onirico e la sua Rappresentazione. In Realtà Virtuale o Visione Reale?, eds. Mariella Dell'Aquila and Agostino De Rosa, 95-124. Napoli: Arte Tipografica.

De Rosa, Agostino. 2000. Dall'Antichità al Medioevo. In La Geometria nell'Immagine. Storia dei Metodi di Rappresentazione, authors Agostino De Rosa, Anna Sgrosso and Andrea Giordano, vol. 1. Torino: UTET.

Gioseffi, Decio. 1957. Perspectiva Artificialis: Per la storia della Prospettiva. Spigolature e Appunti. Trieste: Università Degli Studi di Trieste, Facoltà di Lettere e Filosofia.

Lessing, Gotthold Ephraim. 1775. Lettere Antiquarie.

Mau, August. 1882. Geschichte der Decorativen Wandmalerei in Pompeji. Berlin: G Reimer.

Migliari, Riccardo. 2005. La Prospettiva e Panofsky. In Disegnare Idee Immagini, 31: 28-43.

Panofsky, Erwin. 1927. Die Perspektive als "Symbolische Form”, Berlin: Leipzig. Trad.it. La Prospettiva come Forma Simbolica, ed. Guido D. Neri, (1961). Milano: Feltrinelli.

Pascariello, Maria Ines. 2009. Il Progetto e l'Illusione. Napoli: Nane Edizioni.

Sgrosso, Anna. 1984. Il Problema della Rappresentazione dello Spazio Attraverso i Tempi. Napoli: Giannini.

Wunenburger, Jean-Jacques. 1997. Philosophie des Images. Paris: Edit. Trad. it. Filosofia delle Immagini, (1999). Torino: Einaudi.

Barbara Messina is associate professor of Representation (S.S.D. ICAR17) at University of Salerno, Department of Civil Engineering and she's member of UID (Italian Union for the Drawing). Her research, according with the didactics, is aimed at the descriptive geometry; at the representation as a knowledge system of historical architecture; at the drawing in the digital age. Since 2001 she participates in 
numerous international, national and regional research projects, also as scientific coordinator. Since 1999 she participates, also as speaker, in many conferences of international interest, with papers published in the related proceedings. She is the author of about 60 scientific publications, on topics related to Drawing.

Maria Ines Pascariello is assistant professor of Representation (S.S:D. ICAR/17) at Civil Construction Environment Department of Engineering at the University of Naples. Since 2001 performs Teaching Activities, both Architecture and Engineering Department. The main fields of research and interest are survey and documentation for conservation and development, urban and landscape scale, in order to save and promote cultural heritage. The studies, after graduation to date, the science-disciplinary, deals with the study of Perspective, in particular architectural perspectives and painted architecture of Roman in Pompeii. 